\title{
Insights into chondrule formation processes from EMP and LA-ICP-MS analyses of chondrule in a chondrule from Allende
}

\author{
J. P. Das ${ }^{1}$, D. Trail ${ }^{2}$ and S. L. Baldwin ${ }^{1}$ \\ 1. Department of Earth Sciences, Syracuse University, Syracuse, NY 13244. \\ 2. Department of Earth and Environmental Sciences, University of Rochester, Rochester, 14627.
}

Chondrules, the most abundant constituent of chondrites, are small spherules $(0.1-1 \mathrm{~mm})$ that formed by flash heating of solid precursors at high temperatures ( 1700 to $2100 \mathrm{~K}$ ) followed by quenching at rapid cooling rates $(10$ to $1000 \mathrm{~K} / \mathrm{hr})$ (e.g., [1]). Based on short- and long-lived isotope systematics (e.g., ${ }^{26} \mathrm{Al}-$ ${ }^{26} \mathrm{Mg},{ }^{207} \mathrm{~Pb}-{ }^{206} \mathrm{~Pb}$ ), chondrules formed within 0-3 Ma after the formation of the Sun (e.g., [2]). The high abundance of chondrules suggests that the formation of chondrules was a significant astrophysical event and, therefore understanding chondrule formation will provide clues, to understand the early stages of solar system evolution. Chondrules exhibit a variety of textures based on the conditions of their formation and the nature of precursors. Vital constraints for the chondrule formation mechanism(s) are obtained by investigating the mineralogical and textural properties of chondrules. We present EMP and LA-ICP-MS analyses of an unusual chondrule in a chondrule (CinC) from the Allende chondrite.

A doubly polished slab $(\sim 3 \mathrm{~cm} \times 3 \mathrm{~cm})$ of Allende chondrite was used for surface and chemical characterization using a CAMECA SX-100 electron microprobe (EMP) at the Physical Research Laboratory (PRL) in Ahmedabad. We recognized a unique $\sim 1.5 \mathrm{~mm}$ diameter chondrule that consists of another spherical sub-chondrule $(\sim 600 \mu \mathrm{m})$. Both chondrules show different mineralogy and textures. Detailed backscattered electron images were obtained for the (CinC), followed by determination of major oxides for minerals in the host and the sub-chondrule using a $15 \mathrm{KeV}$ electron beam. We determined $\mathrm{Mg}, \mathrm{Al}, \mathrm{Si}, \mathrm{Ca}$ and Fe concentrations through EMP analysis. Trace element contents were determined using an LA-ICP-MS (Laser Ablation Inductively Coupled Plasma Mass Spectrometer) at the University of Rochester. This instrument consists of a Photon Machine laser ablation unit attached to an Agilent 7900 quadrupole mass spectrometer. The abundances of refractory and moderately volatile elements were determined for minerals in the sub-chondrule and the host chondrule those were selected based on surface and chemical characterization accomplished through electron probe. Concentrations of $\mathrm{Sc}, \mathrm{Ni}, \mathrm{Sr}, \mathrm{Y}, \mathrm{Zr}, \mathrm{Ce}, \mathrm{Eu}, \mathrm{Lu}, \mathrm{Hf}, \mathrm{Mn}, \mathrm{Zn}, \mathrm{Rb}, \mathrm{Cs}$ and $\mathrm{Pb}$ were determined using LA-ICP-MS. Laser fluence was set at $7 \mathrm{~J} / \mathrm{cm}^{2}$ with a pulse rate of $10 \mathrm{~Hz}$, and a He carrier gas was used to transport the analyte from the laser ablation sample chamber to the mass spectrometer. Laser ablation was carried out over a 20 second counting period, with a background counting period of 20 seconds before and after each ablation (e.g., a total mass spectrometer counting period of 60 seconds). Mass ${ }^{24} \mathrm{Mg}$ was used as an internal standard and concentration was standardized against NIST612 glass.

Fig. 1A shows the backscattered electron image of the chondrule in a chondrule (CinC). The subchondrule is a Type IA, i.e., FeO poor chondrule containing porphyritic olivine phases. Olivine phases are forsteritic (Fo95). The sub-chondrule contains drop-shaped Fe-Ni and FeS (troilite) (bright phases, Fig. 1B). The interstitial veins within the porphyritic olivine minerals are rich in metal and/or metal sulfide. The sub-chondrule also consists of mesostasis, the interstitial fine-grained material between the mineral phases, with lamellae of $\mathrm{An}_{77}$. The host chondrule is a Type IB, i.e., FeO poor chondrule containing 200 to $400 \mu \mathrm{m}$ pyroxene crystals, with $\mathrm{En}_{62}$ and $\mathrm{Di}_{36}$ composition. Some pyroxene phases are zoned, with Mg-rich cores and Ca-rich rims (Fig. 1B). Pyroxene crystals are truncated at their grain 
boundaries with the sub-chondrule (Fig. 1B). Unlike the sub-chondrule, the host chondrule consists of higher amount of mesostasis with $\mathrm{An}_{85}$ feldspar lamellae. The thick rim of the host chondrule can be described as aqueously altered phases around the chondrule.

The Ni concentration in olivine from the sub-chondrule ranges from 100 to $5000 \mathrm{ppm}$. For the pyroxene in the host chondrule, the $\mathrm{Ni}$ concentration varies from 25 to $600 \mathrm{ppm}$. On the other hand, Mn concentration for the sub-chondrule olivine phases ranges from 400 to $960 \mathrm{ppm}$. One of the phases was found to be rich in moderately volatile elements, e.g., $\mathrm{Mn}$ is $\sim 6400 \mathrm{ppm}$. The pyroxene from host chondrule contains 500 to 11000 ppm Mn and a higher concentration of moderately volatile elements while the sub-chondrule contains higher refractory elements. Based on variations in the mineralogy, textures, and trace element concentrations, we propose that the precursor material for both the chondrules were different. The sub-chondrule may have experienced longer heating duration than the host chondrule, resulting in loss of volatiles. The presence of porphyritic olivine phases in the subchondrule with negligible amount of mesostasis also supports a longer cooling duration compared to the host chondrule carrying higher amount of mesostasis (i.e., quenched feldspar). Longer cooling rate and almost central location of the sub-chondrule suggest that the sub-chondrule was not completely crystallized when trapped within a chondrule. The presence of truncated pyroxene phases on the boundary of the sub-chondrule indicate that the sub-chondrule might have entered the host chondrule structure with an impact, breaking the existing pyroxene phases.

\section{References:}

[1] R H Hewins et al in " Chondrites and the Protoplanetary Disk, vol. 341 " (Eds. Krot et al.) (2005). Astro. Soc. Pacific Conf. Ser, San Francisco, p. 287.

[2] A N Krot et al,. Geochim. Cosmochim. Acta (2009)73 p. 4963.

[3] JPD is thankful to J. N. Goswami for sponsoring his stay at PRL, Ahmedabad during electron microprobe analysis. JPD acknowledges funding from NASA (grant NNX09AE83G) and Syracuse University.

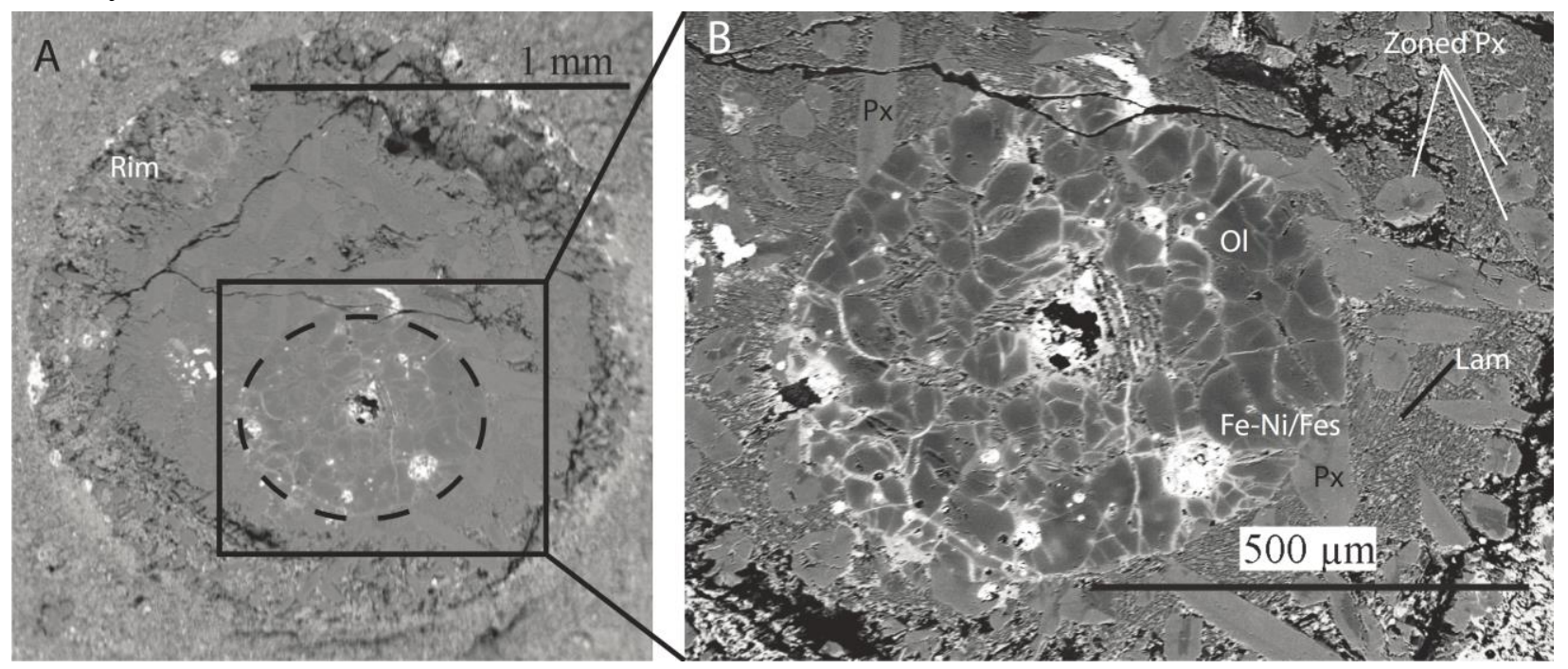

Figure 1. (A) A backscattered electron (BSE) image the Allende chondrite showing a sub-chondrule inside a chondrule $(\mathrm{CinC})$ with a fractured rim. (B) Magnified section of the sub-chondrule containing olivine $\left(\mathrm{Fo}_{95}\right)$ and the host chondrule with pyroxene phases $\left(\mathrm{En}_{62}, \mathrm{Di}_{36}\right)$ and feldspar lamellae $\left(\mathrm{An}_{85}\right)$. Px $=$ pyroxene, $\mathrm{Ol}=$ olivine, $\mathrm{Lam}=$ lamelle. 